\title{
RE: ROSAS!, DEL HOMENAJE POP A LA PROPUESTA INTERACTIVA: EMERGENCIAS ARTÍSTICAS A PARTIR DE LA DOCUMENTACIÓN DE ORIGINALES EFÍMEROS Y RE-APROPIACIÓN
}

\author{
RE:ROSAS!, from pop tribute to interactive proposition: artistic emergencies \\ from documentation of ephemeral originals and re-appropiation \\ Ana Kuntzelman ${ }^{\mathrm{a}}$ \\ Universidad Rey Juan Carlos \\ DOI: http://dx.doi.org/10.15366/secuencias2018.47.001
}

\begin{abstract}
RESUMEN
Este artículo se propone señalar las emergencias artísticas a partir de la documentación y las versiones fílmicas del original coreográfico Rosas danst Rosas, siguiendo las diferentes manifestaciones del proyecto hasta llegar a la propuesta de interacción RE:Rosas!, para mostrar de qué manera estas distintas materialidades generan nuevos espacios de diálogo creativo y una apertura hacia ámbitos de recepción más allá del círculo reducido de la danza contemporánea de vanguardia.
\end{abstract}

Palabras clave: Danza contemporánea, documentación, coreografía, De Keersmaeker, videodanza, Social dance-media, imagen pobre, Re:Rosas!

\section{ABSTRACT}

This article aims to underline the artistic emergencies stemming from documentation and filmic versions of the original choreographic work Rosas danst Rosas following the project's different manifestations up to the interaction proposition RE:Rosas!, in order to show how these different materialities open up new spaces for creative dialogue and an opening unto fields of reception that go beyond the reduced circle of avant-garde contemporary dance.

Keywords: Contemporary Dance, Documentation, Choreography, De Keersmaeker, Screen dance, Social dance-media, Poor Image, Re:Rosas!

[a] Ana Kuntzelman es Doctora en Comunicación por la Universidad Rey Juan Carlos, donde ha presentado la tesis doctoral «La danza tras la revolución: un punto de vista privilegiado sobre el panorama post-digital» (2017). Su trabajo se ha desarrollado principalmente en el ámbito creativo, entre las artes escénicas y la realización audiovisual. Ha trabajado como guionista de ficción en proyectos de diversas productoras (Plural Ent., TVE, LaSexta, etc.), como creadora audiovisual freelance en instituciones culturales (Goethe Institut, Museo Reina Sofía, editorial Klett, etc.), como profesora de danza y, desde 2013, es directora artística de la compañía Snomians. Actualmente compagina su trabajo profesional con la docencia como Profesora Asociada en la Universidad Rey Juan Carlos. 
Rosas danst Rosas es una coreografía creada por Anne Teresa De Keersmaeker y estrenada el 6 de mayo de 1983 en el Théâtre de la Balsamine (Bruselas). Es la pieza fundacional de la compañía Rosas y un hito en la evolución del lenguaje coreográfico europeo de los años ochenta. La propuesta parte de la construcción del movimiento a partir de la combinación de fragmentos que se acumulan en repeticiones pautadas sobre patrones numéricos, a veces inspirados en la música sobre la que trabaja, a veces en otras pautas de construcción geométrica ${ }^{1}$. Los elementos que toma para su trabajo a menudo tienen como recurso movimientos cotidianos (caminar, sentarse, gestualidades reconocibles) y los deconstruye y recombina para colocarlos dentro de otro contexto y, con ello, resignificarlos. Lejos de ser piezas frías en las que predomina una abstracción geométrica que se apoya en las líneas de configuración espacial, las piezas de De Keersmaeker permiten que emerjan nuevos significados a partir de la ejecución singular de los intérpretes, que se ve acentuada por la estrategia de la repetición. Los patrones están puntuados por el cansancio, la mirada, los rasgos performativos de género y el diálogo entre lo que conocemos y lo que se vuelve extraño al resignificarlo o repetirlo, todo lo cual crea un espacio que permite cuestionar nociones construidas sobre el cuerpo, el movimiento y lo femenino ${ }^{2}$.

En 1997, Thierry De Mey, coautor de la música original de la pieza y colaborador habitual de De Keersmaeker, dirige una versión filmada de la coreografía rodada en una vieja escuela de arquitectura de Lieja. La película es más corta que la versión escénica original ${ }^{3}$, y la realización juega con los saltos entre tamaños de planos, que dialogan con la estructura rítmica del movimiento a través del montaje. Además de las cuatro intérpretes para las que está concebida la coreografía, en el vídeo aparecen todas las que habían realizado la pieza a lo largo de su historia. Este trabajo es ya un clásico de la videodanza. En el año 2011 arranca una polémica cuando Beyoncé saca su videoclip para la canción Countdown 4 y la coreógrafa belga la acusa de plagio de parte de sus coreografías Achterland y Rosas danst Rosas ${ }^{5}$. En una versión de YouTube a pantalla partida se pueden ver las similitudes entre el vídeo de Beyoncé y la película de De Mey, de la que toma no solo los movimientos de De Keersmaeker, sino la puesta en escena y el montaje de los planos ${ }^{6}$. Los detalles del litigio no

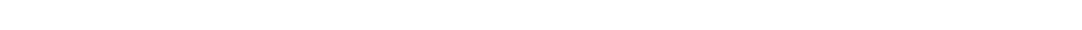
vista con Cvejić (Anne Teresa De Keersmaeker \& Bojana Cvejić. A Choreographer's Score: Fase, Rosas danst Rosas, Elena's Aria, Bartók., pp.79-149).

[3] La película dura 54 minutos, mientras que la coreografía llega casi a las dos horas.

[1] La música está compuesta por Thierry de Mey y Peter Vermeersch, y el trabajo de composición se llevó a cabo en paralelo y en diálogo con el trabajo coreográfico. De Keersmaeker ha descrito en detalle la partitura coreográfica dentro de las entrevistas con Bojana Cvejić en: Anne Teresa De Keersmaeker \& Bojana Cvejić. $A$ Choreographer's Score: Fase, Rosas danst Rosas, Elena's Aria, Bartók. (Gante, Mercatorfonds, 2012). Parte de los vídeos en los que realiza la explicación se pueden encontrar también en YouTube: Rosas vzw, «Rosas danst Rosas- The vocabulary in the second movement.» https://www.youtube. com/watch?v=DVK_5IXOHBU (15/12/2016).

[2] Rosas danst Rosas ha sido comentado en detalle por Ramsay Burt en su estudio acerca de las conexiones entre los creadores de la Judson Dance Church y la obra tanto de De Keersmaeker como de Pina Bausch. En él establece las bases de la estética de De Keersmaeker y reclama los significados que acabamos de señalar en su trabajo coreográfico. Burt se apoya en la idea del paso que supone el trabajo de De Keersameker al cambiar de una clave de trabajo metafórica a otra metonímica. Véase: Ramsay Burt, Judson Dance Theater. Performative traces. (Abingdon and New York, Routledge, 2006). Es interesante comparar las conclusiones de Burt con la descripción que ofrece De Keersmaeker de su propio trabajo en la entre[4] El vídeoclip puede verse en YouTube con los contenidos originales. Véase «Beyoncé-Countdown» <https://www.youtube.com/ watch?v=2XY3AvVgDns $>(10 / 10 / 2015)$.

[5] Los detalles de la reacción de De Keersmaeker se pueden leer en la página de The Performance Club, donde se dio cuenta del proceso: Claudia La Rocco, «Anne Teresa De Keersmaeker responds to Beyonce video». <http://theperformanceclub.org/2011/10/anne-teresa-de-keersmaeker-responds-to-beyonce-video/> (03/07/2015).

[6] El vídeo puede verse en: «Split Screen: Beyonce "Countdown” vs Anne Teresa de Keersmaeker»; <https://www.youtube.com/ watch?v=PDTom514TMw> (04/07/2015). También se observa en él las similitudes entre Achterland y la pieza de Beyoncé. 
[7] Los detalles se pueden consultar a partir del seguimiento en blogs y prensa:

$A B C$ News, «Beyonce Accused of Stealing Dance Moves; Superstar Responds, Saying She Was "Inspired"». < https://www.youtube.com/ watch ? v $=\mathrm{V}_{1} \mathrm{LCYoH}_{3} \mathrm{GwQ}_{\mathrm{W}}>$ (o6/06/2015).

Charlotte Higgins, «Beyoncé pleasant but consumerist, says plagiarism row choreographer». (The Guardian, October 11, 2011). <https://www. theguardian.com/music/2011/ oct/11/beyonce-pleasantconsumerist-plagiarism-row $>$ (o6/o6/2015).

Luke Jennings, «Beyonce v De Keersmaeker: can you copyright a dance move?». (The Guardian, October 11, 2011). https://www.theguardian. com/stage/theatreblog/2011/ oct/11/beyonce-de-keersmaeker-dance-move (06/06/2015). Judith Mackrell, «Beyoncé, De Keersmaeker -and a dace reinvented by everyone». (The Guardian, October 9, 2013).< https://www.theguardian. com/stage/2013/oct/o9/beyonce-de-keersmaeker-technology-dance> (07/06/2015).

James C. McKinley Jr., «Beyoncé accused of plagiarism over video». (The New York Times, October 10, 2011). <https://artsbeat.blogs.nytimes.com/2011/10/10/beyonceaccused-of-plagiarism-overvideo/?_r=3> (06/06/2015).

Matt Truemann, «Beyonce dance moves new video». (The Guardian, October 10, 2011). <https://www.theguardian. com/stage/2011/oct/10/beyonce-dance-moves-new-video > (o7/06/2015).

[8] El proyecto sigue abierto y puede visitarse y subir vídeos. Véase «RE: Rosas» <http:// www.rosasdanstrosas.be/enhome/> (05/07/2015). son el interés principal de este estudio ${ }^{7}$, sino la reacción de De Keersmaeker que, dos años después y con motivo del trigésimo aniversario de Rosas danst Rosas, pone en marcha un proyecto web en el que invita a cualquier persona interesada a aprender la coreografía a partir de tutoriales y reproducirla de la manera que le parezca más adecuada. Las distintas manifestaciones de la pieza y, particularmente, este proyecto, titulado Re: Rosas! ${ }^{8}$, y lo que implica, es lo que nos interesa estudiar en este caso.

En las manifestaciones desde el original pensado para la escena, la película realizada en 1997 por Thierry de Mey, el videoclip de Beyoncé que toma algunos movimientos aislados y parte de la puesta en escena de la película y el proyecto web que abre la interacción con los tutoriales a cualquiera que tenga interés, nos encontramos con una serie de traducciones que permiten reactivar el potencial de la intención creativa inicial para distintos públicos y en distintos contextos de recepción. Para poder analizarlas hay que tener en cuenta el uso de, al menos, tres dispositivos: el dispositivo coreográfico, la cámara y el gran dispositivo de Internet y la Web.

\section{El dispositivo coreográfico: (contra)orden}

En las entrevistas con la dramaturga Bojana Cvejić y los vídeos en los que De Keersmaeker explica en detalle las instrucciones de movimiento - lo hace, además, a la manera de la maestra de escuela, dibujando letras y números con tiza en una pizarra-, nos encontramos con un rigor coreográfico comparable al de las piezas más exigentes de danza clásica, con la única variante de que las unidades de movimiento se apoyan en gran parte en gestualidad cotidiana ${ }^{9}$ y no en posiciones de la convención del ballet. Por otro lado, al explicar el proceso de transmisión de la pieza a una nueva generación de intérpretes, De Keersmaeker señala que se dan diferencias fundamentales que responden a cómo cada una ha entendido el movimiento y lo ha incorporado, algo que pertenece a la intérpre-

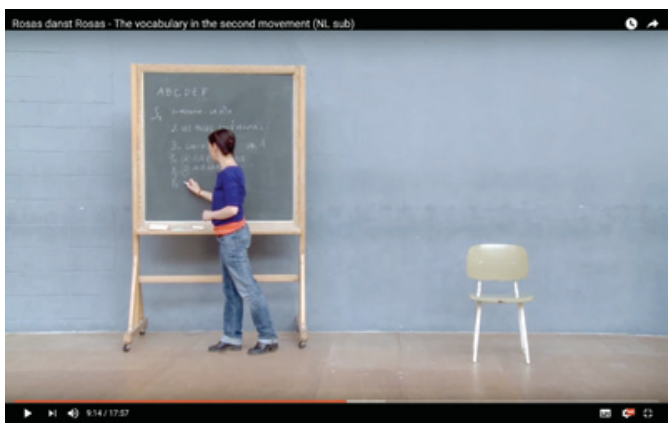

De Keersmaeker explica el funcionamiento de la pieza original con un esquema en la pizarra para el proyecto «A choreographer's score».

[9] «La mayor parte de los movimientos están relacionados con o se derivan de acciones y gestos cotidianos: caminar, sentarse, saludar, girar, tumbarse en el suelo». Anne Teresa De Keersmaeker \& Bojana Cvejić. A Choreographer's Score: Fase, Rosas danst Rosas, Elena's Aria, Bartók., p.84. (La traducción es nuestra). 
te y es distinto en cada caso ${ }^{10}$. Lo que se está poniendo de manifiesto aquí es, por un lado, la primacía del aparato coreográfico y, por otro, todo aquello que se resiste a su ordenación.

El discurso alrededor de la ontología efímera de la danza configura el punto de partida para una buena parte del desarrollo de pensamiento en torno a lo coreográfico desde las reacciones a la danza moderna en los años sesenta ${ }^{11}$. André Lepecki lo resume en los siguientes términos:

Si el movimiento como-lo-imperceptible es lo que lleva al cuerpo que baila a un devenir infinito de disoluciones formales, ¿̇cómo podemos dar testimonio de aquello que perdura en la danza? ¿Cómo conseguimos que la danza permanezca? O, ¿cómo creamos una economía de percepción dirigida específicamente a su desaparición? ${ }^{12}$

En el artículo en el que se incluye esta reflexión, Lepecki explica de qué manera la lucha contra lo coreográfico como el aparato de captura que colapsa las posibilidades del cuerpo en movimiento en una escritura pensada para el control, el archivo y la reproducción es un continuo ir y venir entre la derrota y el reinicio de una deriva. Las propuestas de las creadoras modernas frente al armazón coreográfico del ballet suponen una primera reacción frente a varios siglos de afianzamiento de la danza como creación controlada (fuera del espacio social) que, inevitablemente, vuelve a colapsar en lo coreográfico al cabo del tiempo. La tarea del académico, dice Lepecki, es dar cuenta de este ir y venir del cuerpo en sus múltiples devenires ${ }^{13}$.

El trabajo de Rosas danst Rosas se relaciona con el aparato coreográfico en el sentido que comenta Lepecki, es decir, proponiendo un uso consciente del mismo que permite un discurso complejo y autoconsciente, pero sin dejarse reducir por él. De Keersmaeker utiliza el dispositivo precisamente como herramienta para señalar todo lo que desborda el intento de ordenación de lo visible $^{14}$. Al organizar los movimientos en secuencias de repetición continua evidencia, precisamente, la imposibilidad de esta repetición: la estrategia hace visible la diferencia entre intérpretes y entre el mismo movimiento realizado por la misma intérprete en momentos distintos de la pieza. A pesar de ello, De Keersmaeker señala claramente que lo perdurable del trabajo se apoya siempre en la escritura: «Me ciño a la propia escritura, la soberanía de la estructura que persiste, independientemente de los intérpretes particulares ${ }^{15}$. Lo que debemos preguntarnos entonces es, en primer lugar, de qué manera esta escritura se traduce a un medio distinto y cómo se configura esta nueva materialidad $^{16} ; \mathrm{y}$, en segundo lugar, si la escritura es lo que asegura la permanencia
[10] «La pieza (...) lleva la expresión personal de las intérpretes con las que la diseñé, de sus cuerpos y sus movimientos (...). Por eso es siempre algo delicado cuando la renovamos. A veces echo en falta muchas cosas, otras el proceso hace emerger nuevas cualidades» Anne Teresa De Keersmaeker \& Bojana Cvejić. A Choreographer's Score: Fase, Rosas danst Rosas, Elena's Aria, Bartók., p.115. (La traducción es nuestra).

[11] Para una contextualización del desarrollo del pensamiento en torno a lo efímero en el ámbito de la danza y la performance, véase: Rebecca Schneider, «Los restos de lo escénico (reelaboración).», en Isabel de Naverán (ed.), Hacer historia. Reflexiones desde la práctica de la danza. (Barcelona, Cuerpo de Letra Centro Coreográfico Galego, Mercat de les Flors, Institut del Teatre, 2010), pp. 171-198.

[12] André Lepecki, «Choreography as apparatus of capture.» (TDR: The Drama Review, Vol. 51 [2], 2007), pp. 119-123. (La traducción es nuestra).

[13] Véase André Lepecki, «Choreography as apparatus of capture.»

[14] Al explicar el trabajo de transmisión de la pieza a una nueva generación de intérpretes, De Keersmaeker habla de la necesidad de explicar físicamente «la frontera entre la precisión rigurosa y un sentido anárquico: cómo soltar y estar en control a la misma vez». Anne Teresa De Keersmaeker \& Bojana Cvejić; $A$ Choreographer's Score: Fase, Rosas danst Rosas, Elena's Aria, Bartók., p.115. (La traducción es nuestra).

[15] Anne Teresa De Keersmaeker \& Bojana Cvejić. A Choreographer's Score: Fase, Rosas danst Rosas, Elena's Aria, Bartók., p.115. (La traducción es nuestra).

[16] El concepto de materialidad en este caso está tomado del marco teórico que propone Katja Kwastek, donde se define la materialidad del evento interactivo, que se configura con cada realización individual de la propuesta de interacción, para poder incluirlo dentro de una concepción estética y realizar una interpretación del mismo. Véase: Katja Kwastek, Aesthetics of Interaction in Digital Art. (Cambridge, Massachusetts, The MIT Press, 2015). Lo utilizaremos para referirnos tanto a la coregrafía de De Keersmaeker como a su versión filmada y a las distintas emergencias posteriores en relación a estos trabajos, tanto en el caso de las apropiaciones de Beyoncé como de las respuestas particulares a la propuesta de interacción del proyecto Re:Rosas!. 
[17] En el artículo de Franko «Writing for the Body: Notation, Reconstruction, and Reinvention in Dance» encontramos un valioso resumen de las estrategias de notación a lo largo de la historia de la danza. Franko señala, como ya veíamos en Lepecki, la reacción de la danza moderna frente a los dispositivos coreográficos y audiovisuales: «Las bailarinas modernas han albergado una mística de la presencia que les ha hecho desconfiar del archivo visual.». Franko recela, sin embargo, de esta posición y señala cómo, a pesar de la desconfianza hacia cualquier forma de documentación o notación, sí se da en la práctica de la danza, sobre todo a partir de los años setenta, una transmisión a partir de material de vídeo y no solo oral, además de diversas estrategias de notación. Franko desarrolla sus ideas hasta llegar a la tecnología del motion capture y cómo en esta se trabaja la danza como huella en donde las nociones de cuerpo, lenguaje y gesto serían claves en la descripción de lo que significa «bailar». Véase Mark Franko, «Writing for the Body: Notation, Reconstruction, and Reinvention in Dance.» (Common Knowledge, 17 [2], 2011), pp. 321-334.

[18] Lepecki se apoya en las ideas de Derrida sobre la necesidad de desactivar el proyecto metafísico que gira en torno a la presencia y articular una nueva posibilidad de escritura de la desaparición. Esta escritura, que no se interesa ya por el significante que se refiere a un significado, sino por la huella de una desaparición, nos permitiría, afirma Lepecki, retomar un proyecto de escritura ya no contra lo efímero (que trata de remediarlo), sino junto a. Lepecki sugiere esto como algo

completamente distinto al afán documental, que insiste en la necesidad de preservar la presencia (de asegurar una presencia que resuelva la desaparición de lo efímero). Véase André Lepecki, «Inscribing Dance», en A. Lepecki (ed.), Of the Presence of the Body. Essays on Dance and Performance Theory (Middletowm, Wesleyan University Press, 2004), pp. 124-139.

del trabajo, ¿qué sentido podría tener buscar otros medios de documentación o transmisión de la obra?

\section{Ontología efímera, documentación y performatividad}

Si la coreografía es un aparato de captura, más claramente lo es una cámara. El ejercicio de la notación - tal y como lo practica De Keersmaeker en el proyecto con Cvejić, por ejemplo- y el de la documentación en vídeo de la danza son prácticas cercanas, pero no son del todo equiparables. En la notación reside siempre una voluntad práctica de transmisión. La notación es una forma de memoria, su finalidad es concreta y, muchas veces, precede a la ejecución. El registro filmado es, en cambio, siempre posterior. En la insistencia sobre la condición efímera del original se entiende que hay dos realidades separadas: la del original irrecuperable y la del documento, donde el primero de alguna manera tiene prioridad jerárquica.

La posible relación entre el original efímero y su registro documental se ha articulado alrededor del debate en torno a las nociones de presencia y liveness en el ámbito de lo performativo, tratando de dirimir qué tipo de presencia se da en el evento en vivo y hasta qué punto esta se pierde o es irrecuperable en el registro de ese mismo evento. Desde el ámbito de los estudios de danza encontramos un desarrollo del discurso sobre lo efímero y el evento en autores como, de nuevo, Lepecki o Mark Franko, particularmente en relación con la posibilidad de notación, cita y archivo de la danza ${ }^{17}$. Para estos autores, cuando la condición efímera de la danza se trata como un problema a resolver, se paraliza el desarrollo de los estudios en la materia y de la propia creación. Es a partir de una reconciliación con la idea de lo efímero cuando se empiezan a generar nuevos caminos discursivos y estrategias creativas, y esto se hace posible, en parte, gracias a la incorporación en el discurso de los estudios de danza de las nociones derrideanas de la escritura como la huella y la différance $e^{18}$.

Desde el ámbito artístico y curatorial, este discurso ha dado lugar a iniciativas de creación basadas en la idea de la cita, la lectura y el archivo de lo efímero, muy presentes en los trabajos de creadores como La Ribot, Jerôme Bel, Xavier Le Roy o Boris Charmatz - por citar quizá a los más conocidos de toda una corriente creativa muy activa que cuenta con una enorme comunidad de creadores- y, también en el ámbito nacional, a partir del trabajo de la asociación Artea, que plantea también un archivo de artes efímeras ${ }^{19}$, así como una publicación académica periódica ${ }^{20}$. Así mismo, el proyecto de las naves de Ma-

[19] Los archivos y las distintas publicaciones pueden consultarse en: <http://artesescenicas.uclm.es/index.php> (04/07/2018) .

[20] La revista Efímera es una publicación online y los contenidos están abiertos: < http://www.efimerarevista.es/efimerarevista/index.php/ efimera/index> (07/07/2018). 
tadero Madrid como centro de artes vivas nos habla también de una conciencia y un proyecto claro que se organizan en torno a estas nociones de la centralidad del evento, lo efímero, el encuentro y la participación.

Por otro lado, frente a este trabajo alrededor de lo efímero, hay una serie de autores y de iniciativas creativas y de investigación que señalan la importancia del hecho documental en sí como práctica autónoma ${ }^{21}$. Según Philip Auslander, la tendencia a separar la performance de su documentación es un acto teórico ideológico que se apoya en una idea de «verdad» originaria del hecho performativo inicial, mientras que «la performance es siempre material en bruto para su documentación, que es el producto final que la meterá en circulación y con la que será inevitablemente identificada» ${ }^{22}$. A través de una revisión de distintos ejemplos de documentación de artistas de los años sesenta y setenta, Auslander argumenta cómo, en muchos casos, la performance se hace desde un principio con conciencia de su documentación y casi «para» la documentación. Dada esta situación y el hecho de que esta documentación es la que pone a las performances en relación con un público (quizá no un público privilegiado con acceso al evento original, pero un público al fin y al cabo), Auslander afirma:

Quizá la autenticidad del documento performativo reside en su relación con el observador más que en un supuesto evento original: quizá su autoridad es fenomenológica más que ontológica (...). Podría ser que nuestro sentido de presencia, poder y autenticidad de estas piezas derive no de tratar el documento como un índice de acceso a un evento pasado, sino de percibir el documento en sí como performance que refleja la estética o la sensibilidad del proyecto de un artista para el que somos el público presente ${ }^{23}$.

Por lo tanto, la documentación en sí tiene su propio poder performativo. Hay una relación que se da solo con la documentación del evento y, para la mayoría del público, (especialmente según van pasando los años y en relación con las performances de los años 60/70) esta es la única relación posible. Entonces, si aceptamos que esta documentación lleva a cabo su propio trabajo performativo, ¿en qué consiste y cómo describirlo? En este sentido, Christopher Bedford da un paso más al afirmar que «más allá de las imágenes documentales de las performances, es la integración de estas imágenes en textos descriptivos y analíticos lo que más eficazmente extiende el alcance de la performance ${ }^{24}$. Para Bedford el momento de la performance es simplemente el punto de partida de una cadena viral de reproducciones, comentarios críticos, re-escenificaciones, que hacen que la performance original y lo que plantea se conviertan en un medio mítico con un comportamiento viral. Bedford se refiere a este fenómeno como la «ontología viral de lo performativo», y es lo que nos permite seguir hablando hoy de performances que sucedieron hace más de treinta años ${ }^{25}$. Otros autores, como Amelia Jones, no plantean una ruptura tan radical con la centralidad del evento, pero abren también caminos para integrar un pensamiento alrededor de la documentación y su materialidad ${ }^{26}$.
[21] Los discursos que ponen el acento en la ontología de lo efímero y los que tratan de señalar la relación de la documentación con el original se han planteado en ocasiones como posiciones radicalmente enfrentadas. Aunque este pueda ser el caso entre las posturas de algunos autores concretos, en los últimos años se han dado acercamientos entre unos y otros, como demuestra la aparición de un volumen como el editado en 2012 por Adrian Heathfield y Amelia Jones en el que se recogen artículos y documentos de autores que trabajan en ambas líneas reflexionando sobre la condición y las posibilidades de la documentación del hecho performativo. Véase Adrian Heathfield y Amelia Jones (eds.); Perform, Repeat, Record: Live Art in History. (Bristol, Intellect Books Ltd. Kindle Edition, 2012).

[22] Philip Auslander, "The performativity of performance documentation", en Perform, Repeat, Record: Live Art in History. (Bristol, Intellect, 2012). (La traducción es nuestra).

[23] Philip Auslander, «The performativity of performance documentation».

[24] Christopher Bedford, «The viral ontology of performance», en Perform, Repeat, Record: Live Art in History. (Bristol, Intellect, 2012), Cap. 3.

[25] Christopher Bedford, «The viral ontology of performance», Cap. 3. (La traducción es nuestra).

[26] Véase Amelia Jones, «The Now and the Has Been: Paradoxes of Live Art in History", en Perform, Repeat, Record: Live Art in History, (Bristol, Intellect, 2012). 
[27] El proyecto y los materiales que se han generado en sus distintas fases se pueden consultar en <http://www.capturingdance.de/> (04/07/2018). A partir de las ideas de autores como Auslander y Amelia Jones se articulan las principales líneas de trabajo, que tratan de explorar la importancia del hecho documental y nuevas estrategias de documentanción del proceso artístico.

[28] El proyecto de Tanzfonds Erbe tiene un fuerte apoyo de los fondos de la Unión Europea y lleva varios años desarrollando una tarea de trabajo de recuperación a partir del estudio de la transmisión oral - cuerpo a cuerpo- de la danza del siglo xx. El proyecto está ampliamente documentado y la página web tiene una versión en inglés: <http://tanzfonds.de> (04/07/2018). En septiembre de 2016 su directora, Madeline Ritter, dio una conferencia en Madrid, en el Museo Reina Sofía, dentro del seminario Danza, género y nación: 19301960 (<http://www.museoreinasofia.es/multimedia/danzagenero-nacion-1930-1960-movimiento-como-memoria-sobre-cultura-memoria-danza>) (26/09/2018).

[29] Por ejemplo, en el mes de octubre de 2017 se ha podido ver en el Mercat de les Flors de Barcelona (<http://mercatflors.cat/es/espectacle/rosasdanst-rosas/>) (04/07/2018).

[3o] El proyecto es una adaptación de la coreografía «Vortex Temporum» para un espacio museístico que, desde 2015, ha pasado por WIELS en Bruselas, el Centro Pompidou, la Tate Modern de Londres y el MOMA. En el catálogo online del MOMA se pueden leer los detalles acerca de la misma: <https:// www.moma.org/calendar/ exhibitions $/ 1626$ ?locale $=$ en $>$ (04/07/2018).
Desde el ámbito creativo y curatorial, en este caso y a partir de las ideas de Auslander y Jones principalmente, pero no solo, surge un proyecto tan interesante como es Capturing Dance, ${ }^{27}$ donde se reflexiona sobre las posibilidades creativas a partir de la documentación de la danza -y en este caso no se trata únicamente de la documentación filmada, sino de cualquier tipo de documentación - tanto desde la creación como desde la aportación académica. El proyecto está amparado por el Tanzfonds Erbe (Fondo Patrimonial de la Danza), creado en Alemania para facilitar la transmisión de las coreografías a través de vías innovadoras y para ampliar el conocimiento de la transmisión oral en la danza ${ }^{28}$.

A la luz de estas tendencias discursivas, lo interesante de un proyecto como Rosas danst Rosas - que se ha ido reactivando a lo largo del tiempo en gran parte gracias a la posición privilegiada de la compañía dentro de un entorno apoyado institucionalmente y con el motor que supone el doble trabajo de De Keersmaeker como directora de la compañía y también de la escuela P.A.R.T.S- es que en sus manifestaciones va dando cuenta de las diversas preocupaciones del ámbito de la danza y de las distintas estrategias de supervivencia y auto-reflexión que van apareciendo a lo largo del tiempo. La realización fílmica de la pieza se lleva a cabo en 1997, y esta obra tiene su propio recorrido, pero a día de hoy sigue girando también la versión escénica ${ }^{29}, y$ generaciones de bailarines aprenden rigurosamente la coreografía como parte de su formación. Esto es así con todos los proyectos de Rosas y, por ejemplo, el proyecto Work/Travail/Arbeid ${ }^{30}$ ha supuesto una forma de indagación en la danza como arte visual y las posibilidades de su exhibición en un ámbito museístico y no teatral. Una compañía de esta envergadura puede seguir, e incluso marcar, el paso de las propuestas más innovadoras dialogando con el ámbito académico de forma continua. En este trabajo de diálogo y generación de contenido, inscrito principalmente en el ámbito de la creación contemporánea de vanguardia, cuando empezamos a fijarnos en la vida autónoma de estas formas de documentación vemos que aparecen cruces, choques y conversaciones con las dinámicas culturales del mainstream que ponen en relación ambos mundos y nos hacen ampliar el campo de reflexión.

\section{De la película de arte a la imagen pobre: pérdida de estatus}

La mayor parte de los creadores son capaces de relacionar su trabajo tanto con la noción central de evento efímero, por un lado, como con la necesidad de su documentación, por otro. Tanto por motivos prácticos como por experimentación estética, el trabajo consciente de documentación y generación de materiales muestra que están al tanto de esta necesidad ${ }^{31}$. Además, los creadores no

[31] En muchas ocasiones, lo que marca la práctica artística viene señalado por las exigencias del contexto cultural y la economía en la que esa práctica se inscribe. Es fundamental tener en cuenta que la mayor parte de los festivales y los teatros que exhiben danza suelen exigir, como paso previo a la posible contratación, el visionado de una grabación de la pieza. Esto ya genera una necesidad ineludible de documentación, más allá de la voluntad de registro para la posteridad o de los ejercicios de traducción formal. 
siempre consideran cuestiones de «pureza» en sus referentes e influencias ${ }^{32}$. Por otro lado, la desconfianza frente a la imagen filmada no es característica únicamente de las pioneras de la danza moderna, como señalaban Franko y Lepecki, sino que ha sido una cuestión comentada a lo largo de la historia por distintos bailarines y coreógrafos, como recoge Erin Brannigan en su exhaustivo trabajo sobre danza para la cámara ${ }^{33}$. Según Brannigan, el discurso sobre la presencia de los cuerpos cinemáticos debe partir de la consideración de una corporalidad que existe solo en la videodanza:

La presencia en-pantalla del cuerpo que baila es el producto de una génesis fílmica, que existe solo «para la pantalla, su cine». (...) Esta producción [requiere de] una variedad de operaciones cinecoreográficas donde vemos a los elementos coreográficos escritos a través del dispositivo cinemático ${ }^{34}$.

Es decir, una vez se da la re-escritura de los elementos coreográficos a partir del dispositivo cinematográfico ya estamos ante otra materialidad y no tiene sentido tratar de compararla con un referente efímero ${ }^{35}$. El plagio por parte de Beyoncé que denuncia De Keersmaeker tiene que ver con dos materiales fílmicos que, si seguimos la lógica de Brannigan, funcionan con total autonomía respecto de sus originales coreográficos. Se afirman en su propia materialidad, por un lado, la película de Thierry de Mey, Rosas danst Rosas, y, por otro, la película Achterland, en la que se recoge la coreografía del mismo nombre. Las diferencias entre ambas son importantes, ya que la primera lleva a cabo un replanteamiento completo de la puesta en escena en su adaptación al formato fílmico, separándose del planteamiento escénico de manera más clara, mientras que la otra se ciñe a la configuración espacial del original, manteniendo la puesta en escena teatral. Ambas, en cualquier caso, son emergencias artísticas autónomas en su medio, más allá de su relación con la pieza coreográfica original. Están situadas en el ámbito de la videodanza más que en el de la documentación y, en ese sentido, tienen otro estatus ${ }^{36}$. El rastro que estamos intentando seguir en este caso nos lleva, en el paso de estas piezas al videoclip de Beyoncé, a hablar de una re-elaboración del material a partir de un original fílmico, ya escindido de su referente coreográfico original.

Cuando Adria Petty, la realizadora del vídeo de Beyoncé, le propone a esta inspirarse en las imágenes de Thierry de Mey, el referente ya es audiovisual, y el movimiento se va a traducir en un proyecto de las mismas características. Beyoncé toma parte de la puesta en escena que aparece en la película de De Mey: plantea la localización en un edificio muy similar a la escuela de Lieja, el vestuario es muy parecido e incluso los planos de cámara similares. Cambia, por otro lado, la lógica coral de la coreografía de De Keersmaeker y se coloca a sí misma como elemento central alrededor del cual se mueve el coro de bailarinas. Incluye, además, varios planos rápidos en los que aparecen movimientos de ballet (un grand jeté y varias piruetas) que no estaban en la versión de De Keersmaeker y que sirven como puntuación del ritmo del montaje con la música. Cambia también el juego complejo de contrapunto entre la música y el movimiento que plantea el original
[32] Cuando Cvejić le pregunta a De Keersmaeker de qué manera la danza posmoderna americana le había influido en la creación de Rosas danst Rosas, De Keersmaeker responde que, en el momento de realizar la pieza, aún no estaba familiarizada con aquellos trabajos. En cambio, sí menciona Tiempos Modernos de Charles Chaplin (Modern Times, 1936) y las películas de Busby Berkeley como clara fuente de inspiración. (Anne Teresa De Keersmaeker \& Bojana Cvejić. A Choreographer's Score: Fase, Rosas danst Rosas, Elena's Aria, Bartók., pp. 81, 85 y 93).

[33] La autora recoge testimonios de bailarines y coreógrafos que han hablado sobre el trabajo para la cámara y la dificultad de traducción de la danza a su registro fílmico, entre otros, Gene Kelly, Daniel Nagrin.

[34] Erin Brannigan, Dance on Film. Choreography and the Moving Image. (New York, Oxford University Press, 2011), p.11. (La traducción es nuestra).

[35] Véase Erin Brannigan, Dance on Film. Choreography and the Moving Image.

[36] Más allá de un estatus que tiene que ver con un valor artístico superior y que nos obligaría a abrir otra línea de discurso mucho más compleja acerca de cómo se decide este estatus, debemos fijarnos en lo más prosaico: en el acto documental -el material se considera de segunda o residual frente al evento, y los nombres de los realizadores y fotógrafos que realizan el acto documental no aparecen reseñados- esas agencias se pierden. En el caso de las dos películas que estamos comentando, ambas tienen una dirección con nombre y apellidos y un equipo técnico y artístico que aparece en los títulos de crédito. La imagen de registro práctico no entra en la categoría de obra, mientras sí lo hacen las realizaciones consideradas como vídeo danza. 
[37] Beyoncé lo explica en las declaraciones que aparecen citadas en The Guardian: «Adria Petty, la codirectora, me enseñó el ballet contemporáneo de hace casi treinta años. Me pareció refrescante, interesante y atemporal. Siempre me ha fascinado la manera en la que el arte contemporáneo utiliza diferentes elementos y referencias para producir algo único. El vídeo tiene ya casi dos millones de visitas, así que espero que los fans observen todos estos homenajes y que descubran a Audrey Hepburn, Warhol, Bardot, Rosas danst Rosas y todas las obras que inspiraron y dieron forma a este video». Charlotte Higgins, « Beyoncé pleasant but consumerist, says plagiarism row choreographer». (La traducción es nuestra).

[38] «Al ver a Beyoncé bailando [Rosas danst Rosas], lo encuentro agradable, pero se queda plano. Es agradable a la manera de un entretenimiento de consumo.» Claudia La Rocco, «Anne Teresa De Keersmaeker responds to Beyonce video". (La traducción es nuestra).

[39] La comparación entre ambos puede verse en «B e y o n c e-Coun t d own (Original VS Alternative)» <https://www.youtube.com/ watch?v=9wHWIPLE 3 IM > (09/09/2017).

[40] Anne Teresa de Keersmaeker Early Works [DVD] (Cineart, 2013).

[41] «La imagen pobre encarna la otra vida de lo que fueron obras maestras del cine y del vídeoarte. Ha sido expulsada del paraíso protegido que fue una vez el cine (...). La imagen pobre no tiene que ver ya con la cosa real -el original originario-. En cambio, tiene que ver con sus propias condiciones de existencia: circulación en enjambre, dispersión digital, temporalidades fragmentadas y

flexibles. Tiene que ver con el desafío y la apropiación tanto como con el conformismo y la explotación». Hito Steyerl, «In defense of the poor image» (e-flux Journal, 10, 2009): <http://www.e-flux.com/journal/10/61362/in-defense-of-the-poor-image/> (o4/o7/2018). (La traducción es nuestra).

y utiliza una puntuación que acentúa los golpes de ritmo de su propia canción. Todo ello se integra con el resto del contenido del videoclip, que utiliza varios referentes más y hace guiños a distintas secuencias de películas clásicas.

Cuando De Keersmaeker denuncia el plagio, Beyoncé responde que se ha inspirado en la obra de la belga para hacer su propia creación original y que no se trata de un plagio, sino, más bien, de un homenaje, uno entre tantos que hay en el vídeo. Se refiere, también, a cómo el arte contemporáneo toma de muchas fuentes para crear obras originales y que, dado que el vídeo lo han visto ya casi dos millones de personas, espera que los fans sepan apreciar los muchos homenajes a creadores contemporáneos que contiene el trabajo y no solo el de De Keersmaeker ${ }^{37}$. Las afirmaciones de Beyoncé funcionan como una desestimación de la denuncia de De Keersmaeker, casi como si fuera una rabieta, insinuando que quizá debiera estar agradecida por ser homenajeada y ver su obra expuesta a un público que, si no, jamás le prestaría atención. Por su parte, De Keersmaeker da a entender que Beyoncé no ha entendido nada del planteamiento original de la obra, porque, en su versión, el potencial crítico original se ha perdido ${ }^{38}$. No conocemos los detalles de las negociaciones entre los respectivos equipos legales o asesores de las creadoras, pero por los resultados puede parecer que la polémica se ha movido más en un entorno de diálogo que de enfrentamiento. El vídeo de Countdown sigue en circulación - a pesar de que en un primer momento apareció una versión en la que se habían quitado las partes que correspondían a las coreografías de De Keersmaeker ${ }^{39}-$, pero en las nominaciones a los premios de la MTV a la mejor coreografía del año 2012, entre las que estaba Countdown, aparece el nombre de De Keersmaeker junto al resto de los coreógrafos que han participado en el vídeo. Eso sí, en último lugar.

Pero hay un paso intermedio que cambia completamente las reglas del juego y que no sabemos exactamente cuándo se produce en la línea temporal. En algún momento después de la realización de las versiones fílmicas de Rosas danst Rosas y de Achterland, estos documentos cambian de estatus. Ambas piezas arrancan su circulación pública como creaciones de vanguardia artística que se exhiben, principalmente, en festivales especializados y canales de arte en televisiones europeas. Tienen también, al menos en el caso de Rosas danst Rosas, una comercialización primero en VHS y luego en $\mathrm{DVD}^{40}$, pero, cuando surge la polémica en torno a Countdown, las imágenes de referencia (es decir, las que el público y los periodistas consultan para comprobar si efectivamente ha habido plagio) ya no son las que están contenidas en esos formatos, sino las versiones que circulan libremente por internet, en fragmentos muchas de ellas, y en una calidad mucho peor que la original. Cuando entramos de lleno en el debate sobre el plagio, se ha operado de nuevo un cambio en el modo de circulación del contenido y estamos ya ante lo que Hito Steyerl ha denominado una «imagen pobre ${ }^{41}$. El formato contenedor desaparece, y las imágenes son 
datos comprimidos, descargados y manipulados que circulan sin control por la web. Navegando por YouTube pronto descubrimos que Rosas danst Rosas se puede reconstruir casi al completo a partir de todos los fragmentos que circulan por distintos canales y que Achterland está en versión completa en un solo archivo.

Para una gran parte de los interesados en la obra de De Keersameker estas imágenes «pobres» llevan siendo las únicas imágenes de referencia, mucho antes de que surgiera el problema con Beyoncé. Incluso es posible que fueran las que usó de referencia la propia Beyoncé en su búsqueda de inspiración creativa junto a la directora del videoclip, Adria Petty, que comenta en una entrevista a la MTV cómo la mayor parte de las referencias con las que trabajaron fueron de danza expresionista alemana $^{42}$. El no poder señalar el momento exacto en el que una imagen «rica» aparece en su versión «pobre» en la economía de circulación de internet es también algo característico de esta, puesto que no hay una regulación ni un registro. En el fenómeno, tal y como lo describe Steyerl, se dan varias tensiones contrapuestas: por un lado, la imagen «pobre» permite un acceso universal a contenidos que han dejado de ser accesibles (parcialmente por la desaparición de programas de protección estatal de la cultura y los productos culturales menos populares) y, al ser manipulable, convierte a los receptores en productores, editores y creadores potenciales; por otro lado, forma parte de un contexto asediado por intereses económicos que realizan intentos continuos de privatización y optimización comercial de los canales.

En el ámbito de la danza, la existencia no reconocida de versiones «pobres» es un fenómeno que la mayor parte de las creadoras contemporáneas de danza han ignorado. Las compañías no viven de los derechos de las imágenes, y la persecución del pirateo, como se da en el ámbito de la creación cinematográfica, por ejemplo, no ha sido un elemento tan problemático. Las versiones que circulaban libremente por internet eran, en el mejor de los casos, una prueba del interés por la creación original y, en el peor, un fragmento corto de ínfima calidad en el que era difícil apreciar el contenido. De Keersmaeker y su equipo han experimentado en numerosas ocasiones con distintos medios y distintas materialidades, pero estos ejercicios se movían siempre en el territorio controlado de la creación de vanguardia y élite cultural europea. La apropiación por parte de Beyoncé desencadena una atención renovada sobre este ámbito de la imagen «lumpen-proletaria», como la denomina Steyerl, porque con ella se recupera la imagen de esta
[42] Las declaraciones completas se encuentran en la entrevista para la MTV: Jocelyn Vena, «Beyonce's 'Countdown' Video Shoot Was 'Evolving, Spontaneous'» (07/10/2011) <http:// www.mtv.com/news/1672200/ beyonce-countdown-videoshoot/ > (09/09/2017). 
[43] Véase Claudia Kappenberg, "The Logic of the Copy, from Appropriation to Choreography" (The International Journal of ScreenDance, 1, 2010), p. 27.

[44] Anthea Kraut, Choreographing Copyright Race, Gender, and Intellectual Property Rights in American Dance. (Nueva York, Oxford University Press Kindle Edition, 2016), p. 264. (La traducción es nuestra).

[45] Véase Anthea Kraut, Choreographing Copyright Race, Gender, and Intellectual Property Rights in American Dance.

[46] Harmony Bench, «Screendance 2.0: Social Dance-Media» (Participations. Journal of Audience and Reception Studies, 7 [2]), p. 184. (La traducción es nuestra). circulación de lo viral para generar un negocio millonario. Dos creadoras vivas, de ámbitos culturales casi contrapuestos, se encuentran en un cruce de caminos que cuestiona nociones de propiedad y que da la vuelta a dinámicas históricas de apropiación de lo popular por parte de la alta cultura. Esta es una amenaza real sobre el control de los contenidos y de los recursos que estos generan. De Keersmaeker reacciona ante esta amenaza con estrategias legales, pero, al cabo del tiempo, también este conflicto desemboca en el proyecto Re:Rosas!, fruto de una reflexión sobre las potencialidades de este nuevo contexto cultural.

\section{Del videoclip al proyecto interactivo o la coreografía en la era del tutorial web}

Como señala Claudia Kappenberg, en la lógica de producción de los videoclips, efectivamente se da por sentada una forma de comentario y cita que toma de referentes sin hacer mención del original, en un ejercicio continuo de remix y apropiación ${ }^{43}$. La obra de De Keersmaeker, al convertirse en imagen «pobre», entra en la economía de circulación de internet, que supone un nuevo contexto cultural donde las cuestiones de autoría se vuelven menos claras. En el estudio de Anthea Kraut sobre la historia del copyright en la danza americana a lo largo del siglo xx, la autora incluye en la coda una descripción detallada de este conflicto entre Beyoncé y De Keersmaeker:

Las acciones coreográficas de Beyoncé en Countdown - convirtiendo a la vanguardia blanca en material para su propia producción cultural- dan la vuelta al guion que durante tanto tiempo ha autorizado a los artistas blancos a tomar de los no-blancos y a la «alta cultura» a tomar prestado de «la baja cultura ${ }^{44}$.

Kraut argumenta cómo, a pesar de la gran maquinaria comercial que maneja Beyoncé y de las muchas pegas que ve a sus acciones, su apropiación no deja de ser una especie de ataque inesperado al mundo habitualmente protegido de la creación de vanguardia, más habituada a apropiarse de referentes populares que a ser víctima de ellos. Además, añade, la puesta en circulación de los movimientos de De Keersmaeker los integra en una economía reproductiva de internet, donde las normas son otras y la circulación entre distintos cuerpos se hace posible a través del fenómeno de la «social dance-media» ${ }^{45}$. La noción de «social dance-media» la toma Kraut de la autora Harmony Bench, según la cual:

[las social dance-media] reconfiguran la danza como lugar para el intercambio social y la participación al proporcionar vehículos para compartir y hacer circular la danza. (...) Las obras de social dance-media se presentan como evidencias de que la danza debería ser compartida, copiada, encarnada, manipulada y recirculada antes que preservada para el profesional y el bailarín de élite ${ }^{46}$.

Para ilustrar el funcionamiento de la misma, Bench pone como ejemplo el concurso que propuso a sus fans Beyoncé, en el que les animaba a tratar 
de hacer la mejor imitación de la coreografía de su vídeo All the single ladies ${ }^{47}$, y afirma que esta coreografía circula por los dormitorios estadounidenses a través de la cultura popular como si hubiera sido creada de forma comunal y no estuviera sujeta a leyes de copyright ${ }^{48}$. Precisamente esto es lo que lleva a Kraut a insinuar que, en contraste, el intento de De Keersmaeker de organizar un fenómeno espontáneo como el social dance-media a partir de tutoriales y de una plataforma que recibe y archiva las versiones de los receptores es más un intento de control que de diseminación. Para poder valorar esta afirmación debemos primero fijarnos en qué es lo que propone De Keersmaeker cuando publica la web RE:Rosas!.

$R E: R o s a s !$ consiste en una web en la que De Keersmaeker, asistida por varias integrantes de su compañía, se apoya en la lógica del tutorial para explicar la historia de la pieza Rosas danst Rosas y su mecánica coreográfica para que cualquiera pueda hacer su propia versión. Toda la explicación inicial de cómo realizarla se ha colocado en cuatro vídeos denominados «introducción», «movimientos», «estructura» y «coreografía». Los cuatro duran en total unos treinta minutos. Muy probablemente hacen falta varios visionados de los vídeos (paradas, vueltas atrás, repeticiones) para poder aprender las partes y los tiempos y, luego, hace falta un trabajo autónomo de repetición de los movimientos y coordinación antes de grabarlos. Desconocemos los tiempos concretos de interacción de cada grupo de receptores, pero sí podemos intuir que el proyecto demanda un proceso prolongado para llegar a materializar una respuesta. No tenemos los datos de aquellos que han intentado realizar una versión, pero se han quedado a medio camino o que, simplemente, han visionado los tutoriales sin animarse a probar el movimiento. Como testimonio quedan los $386^{49}$ vídeos de aquellos que sí han completado el proceso.
[47] All the single ladies está dirigido por Jake Nava y coreografiado por Frank Gatson y Jaquel Knight. Se estrenó en octubre de 2008 en la MTV. La versión que actualmente aparece en el canal oficial de Beyoncé en YouTube es de octubre de 2009. Ver «Beyoncé- Single Ladies (Put a Ring on it) (Video Version)» <https://www.youtube.com/ watch?v=4 m1EFMoRFvY > (09/03/2018).

[48] «La coreografía de The Single Ladies, como la de Thriller anteriormente, se mueve a través de la cultura popular y de los dormitorios americanos como si hubiera sido creada y apropiada comunalmente y no estuviera sujeta a copyright.» Harmony Bench, «Screendance 2.0: Social Dance-Media». (La traducción es nuestra).

[49] El número de vídeos se ha ido incrementando a lo largo del tiempo, y este número es a 30 de marzo de 2018
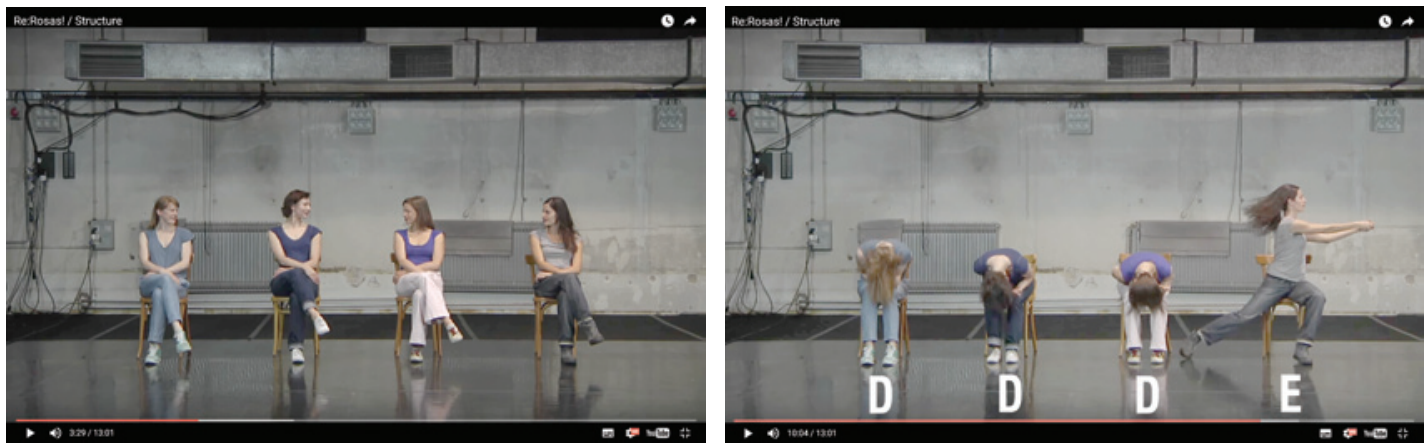

Momento de la explicación en el tutorial de la coreografía Rosas danst Rosas. 
[50] Señalamos esto porque es importante reconocer que el formato del tutorial no es una solución universal de transmisión y no sería un recurso eficaz en muchos casos, por ejemplo, para transmitir la lógica de creación de piezas creadas a partir de improvisaciones con los intérpretes.

[51] Por otro lado, es importante matizar que el proyecto de $R E: R O S A S ! !$ no recoge el planteamiento coreográfico completo de la pieza original, sino partes escogidas de cada sección. En ese sentido la apertura del código es parcial.

[52] Con esto no pretendemos hacer un juicio de valor, en el que se desestima el fenómeno viral o la apropiación cultural y se ensalza la posibilidad de reflexión tal y como la plantea el proyecto de De Keersmaker. Simplemente creemos que es importante matizar que son cosas distintas y abren caminos distintos de relación entre creadores y público, y entre obra y público.
En una analogía con la lógica de lo digital, podríamos decir que el planteamiento coreográfico de De Keersmaeker es algorítmico, porque trabaja con la combinación y la repetición de instrucciones más o menos sencillas para obtener un resultado complejo que se genera por esa acumulación de acciones. Quizá por ello su trabajo se adapta particularmente bien a un formato como el del tutorial, donde la mecánica de transmisión consiste en desglosar las instrucciones de trabajo ${ }^{50}$. En cualquier caso, lo que nos interesa señalar es cómo esto permite a los receptores una relación directa con los instrumentos coreográficos, lo cual supone una forma de interacción distinta a la social dance-media y a la apropiación de contenidos que comentábamos anteriormente, donde el proceso viral se apoya en las imágenes y no en las instrucciones. De alguna manera, con este proyecto la coreografía se vuelve de código abierto, y cualquiera puede acceder a ella ${ }^{51}$. La reproducción de la misma se aleja en este caso del comportamiento viral y se coloca en un espacio de reflexión ${ }^{52}$. De Keersmaeker comparte el sistema para que cualquiera pueda interactuar con él, a diferencia de compartir el resultado de una interacción específica (la de su compañía) con las instrucciones del mismo. Este salto es el que nos acerca a la estética del arte interactivo, en el cual la materialidad de la propuesta de interacción emerge con cada realización del potencial del sistema de interacción por parte de un receptor. Así, en las respuestas que aparecen en Re:Rosas! encontramos una variedad de resultados que ya no podemos interpretar dentro del marco de la apropiación, sino que apuntan a una interacción más compleja que se articula en torno a la ejecución de las instrucciones que propone el proyecto y todas las variaciones sobre las mismas. Hay propuestas que solo elaboran una parte de las instrucciones que propone De Keersmaeker, incluso un solo movimiento para dar pie luego a una interpretación completamente distinta. En algunas es completamente reconocible el movimiento original, y en otras eso ha dado pie a versiones libres que, si no estuvieran dentro del proyecto y se propusieran como respuesta al mismo, posiblemente, jamás asociaríamos. Hay versiones de numerosas escuelas de danza que tratan de ser fieles al original y hay versiones que fusionan algunos movimientos con otros estilos como el de Bollywood. No hay una línea consistente de repetición, y el original es una huella lejana, cuando no completamente borrada. Hay incluso una versión de animación $3 \mathrm{D}$ en la que las sillas realizan las pautas coreográficas. El material de partida es un código que forma parte de una propuesta de interacción que se puede activar para dar pie a resultados muy divergentes. Ya no estamos ante la viralidad del documento audiovisual, sino ante una obra interactiva, tal y como lo describe Katja Kwastek:

(...) el arte interactivo cuestiona categorías fundamentales de la estética del arte: la obra como su objeto de estudio principal, la distancia estética como su condición y la distinción entre percepción sensorial, conocimiento cognitivo y acción voluntaria como sus elementos básicos. Porque, por un lado, la obra se basa en una propuesta de interacción configurada artísticamente, mientras que, por el otro, su realización depende de la acción del receptor. La materialidad, la gestalt y la interpretabilidad de la obra deben ser activadas y experi- 
mentadas de forma individual para que los procesos epistémicos puedan darse. (...) [La obra de arte interactiva] se parece al juego, con el que comparte la formación de la gestalt a partir de un proceso, su fundación sobre un sistema de reglas y su relación ambivalente con la «realidad». Pero, a diferencia del juego, engendra disrupciones y colisiones de marcos de referencia, así como hace uso de diferentes formas de auto-referencialidad. ${ }^{53}$

Es particularmente en esta última distinción entre la obra interactiva y el juego donde encontramos la clave diferenciadora. El proyecto se apoya en dos dinámicas bien conocidas de la realidad digital (los tutoriales y los memes) y, con ello, se explica a sí mismo. Además, anima a los participantes a enviar sus respuestas para incluirlas dentro de la propia web. Esta dinámica de «pastoreo» de una circulación que suele ser descontrolada y viral puede leerse, como señalaba Kraut, como una mera excusa de autocelebración para una compañía en su trigésimo aniversario o como reclamo autoritario de una propiedad creativa por parte de la autora original. Estas son, efectivamente, lecturas posibles del proyecto, pero es importante señalar que, al entrar en relación con lo que se propone -el proceso coreográfico detallado-, se abre también al receptor una posibilidad de autoconocimiento y de reflexión sobre lo que supone la construcción coreográfica y el trabajo del cuerpo en relación a ella que va más allá de la réplica del meme, porque no tiene como objetivo principal la repetición y contiene una información más detallada por parte de la creadora, lo cual favorece un diálogo más extenso e, incluso, la posibilidad de crítica $^{54}$. Con su propuesta De Keersmaeker trata de abrir la posibilidad a cualquiera de reinterpretar su coreografía, al igual que ha hecho Beyoncé, pero a la vez fractura este marco de referencia de lo viral, porque, al hacer accesible la lógica creativa a cualquiera que esté interesado, lo que está poniendo de manifiesto es que no es la repetición, sino la interacción con las reglas propuestas, lo que configura la clave del proyecto. En el centro de lo que se propone no está la viralidad, sino el diálogo y la reflexión.

Claudia Kappenberg, comentando las ideas de Walter Benjamin y en una línea cercana a la expuesta por Brannigan, habla de la posibilidad de una experiencia aurática a partir de la copia en circulación. Siguiendo las ideas de la antropóloga Nadia Seremetakis, Kappenberg comenta la relación entre el flujo continuo de información y la posibilidad de una suspensión momentánea de los modos de representación habituales como forma de dar espacio a la experiencia individual para que esta pueda articularse ${ }^{55}$. Una idea similar es la que propone Katja Kwastek cuando define la obra de arte interactiva como proceso que habilita una distancia epistémica y, con ello, la distingue de las propuestas interactivas comerciales o los videojuegos de inmersión ${ }^{56}$. El tutorial reclama una autoridad (la que imparte él mismo), pero es siempre una autoridad transitoria ${ }^{57}$. Hay un ejercicio de control en el hecho de querer conducir la manera en la que se disemina/explica la propia obra, indudablemente, pero también hay una consideración del otro como interlocutor viable, como autor de su propia interpretación que es capaz y que, a partir del cono-
[53] Katja Kwastek, Aesthetics of Interaction in Digital Art, (Cambridge, Mass., The MIT Press, 2015), p. 261. (La traducción es nuestra)

[54] El esfuerzo de traducción del movimiento a una serie de datos de las creaciones de danza por parte de distintos autores no es un proceso nuevo. Proyectos como Improvisation Technologies, de William Forsythe, o el grupo de trabajo Motionbank (<http://motionbank.org/>) - por citar algunos de los más conocidos- son reflexiones acerca de lo coreográfico en su traducción a valores numéricos que permiten trabajar en otros medios. Lo que es distinto en el caso del proyecto RE:ROSAS!! es la voluntad de comunicación directa, el puente que se establece entre la reflexión en profundidad y la transmisión abierta del tutorial.

[55] Véase Claudia Kappenberg, "The Logic of the Copy, from Appropriation to Choreography».

[56] Véase Katja Kwastek, Aesthetics of Interaction in Digital Art.

[57] La lógica del tutorial no es la del maestro que tiene el conocimiento como propiedad, sino la de un igual que comparte datos parciales o modos de hacer con otros iguales. No es la misma De Keersmaeker la que explica la coreografía completa en el proyecto con Bojana Cvejić que la que imparte el tutorial, y no porque esta segunda sea condescendiente, sino porque está abriendo la posibilidad de un diálogo plural. 


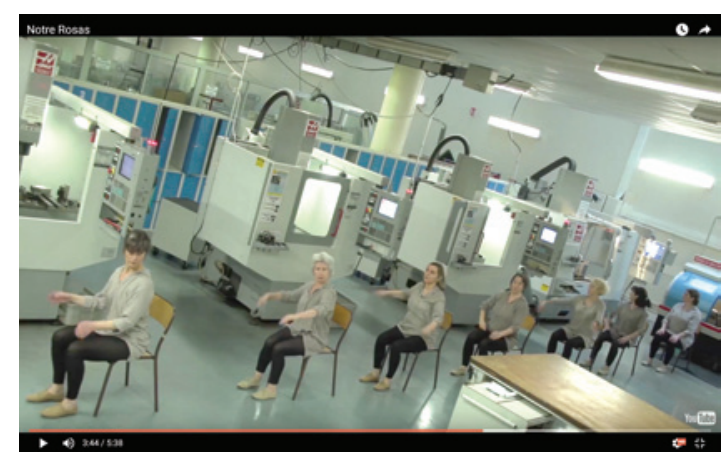

Una de las versiones de Rosas danst Rosas realizadas a partir de los tutoriales.

cimiento compartido, puede generar propuestas de igual valor, aunque no tengan ninguna relación de similitud con el original. Beyoncé proponía a sus fans un ejercicio de reproducción del original en el contexto de la social dance-media, y la regla principal era mantenerse fiel a los movimientos originales; lo que De Keersmaeker propone es más bien la explicación de la mecánica profunda de la pieza, la cual puede dar lugar a versiones fieles o no, porque lo importante es no perder el potencial de reflexión. En ambos casos se da un proceso de encarnación y trabajo físico análogo al que llevan a cabo las intérpretes que la han realizado en escena, pero las reglas del juego y sus objetivos son muy distintos, y esto es lo que las separa. Re:Rosas! posibilita, como hace el fenómeno de la social dance-media, una circulación libre de la danza, pero reclama, sobre todo, un tiempo para pensar esa danza, la danza como forma de discurso y de pensamiento y, en este sentido, habilita un proceso epistémico que no forma parte de la circulación descontextualizada a partir de apropiaciones comerciales o virales. Además, Re:Rosas! supone un paso en una dirección apenas explorada por la danza de vanguardia: la divulgación popular de sus lógicas de creación a través del medio digital y el registro audiovisual. Cuando De Keersmaeker comenta en un primer momento lo que ella considera el plagio de Beyoncé, se pregunta si hacen falta treinta años para que una creación de vanguardia pueda entrar a formar parte del imaginario popular. Quizá con pasos similares al que se da con Re:Rosas! esos tiempos podrían verse alterados y las barreras que aún protegen/aíslan a la vanguardia cultural podrían fracturarse para permitir accesos directos e interacciones en profundidad con sus lógicas de creación.

\section{Conclusiones: la necesidad de explorar}

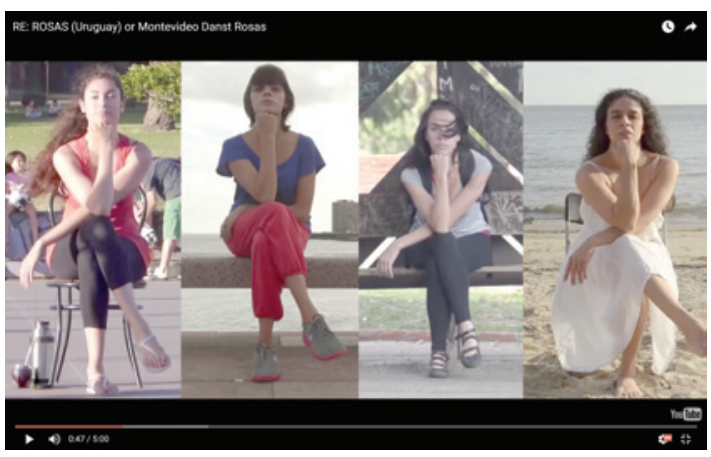

Versión de Rosas danst Rosas enviada desde Uruguay.
Existe una necesidad de reflexión sobre el formato documental de la danza $-\mathrm{y}$ su circulación- no como un registro fidedigno del original, sino como una materialidad completamente distinta que, empero, permite nuevas formas de relación con la propia obra y, sobre todo, con el público en una realidad que, de pasar inadvertida o ignorada, amenaza con dejar a la danza recluida en un entorno cerrado de creación elitista y diseminación reducida. Cuando esto se convierte en una preocupación 
principal, el trabajo de los creadores y el apoyo del discurso se ve de forma creciente forzado a hablar el idioma vernáculo de la web, sin perder de vista el discurso crítico y la complejidad de la obra. Esto es difícil de hacer sin apoyo institucional, pero es fundamental para asegurar una pervivencia de creaciones que, de otra manera, se pierden o se documentan con pocos medios y en peores circunstancias. La situación privilegiada de una compañía como Rosas, que cuenta con un inmenso apoyo institucional, permite una práctica documental profesional y, en sus propios términos, más pensada para el archivo de la compañía y la experimentación formal que para la comercialización de las piezas; pero una vez ese material empieza a circular pierde rápidamente su estatus de imagen con pedigrí y entra con facilidad en la economía de lo que Hito Steyerl ha denominado la «imagen pobre». Proyectos interactivos como Re:Rosas! crean ámbitos de exploración intermedios para nuevas materialidades propias de la economía cultural de internet que presentan un potencial de diseminación, comentario, reflexión y también de reconfiguración sin precedentes. Además de las dinámicas virales y de apropiación que se dan de forma más o menos espontánea por las características técnicas de las plataformas de diseminación de contenidos, y como contrapunto a las tensiones comerciales que asedian de manera cada vez más voraz estas mismas plataformas, el esfuerzo por romper las barreras aún existentes entre la creación de vanguardia y la divulgación popular posibilita nuevos ámbitos de creación y reflexión que pueden funcionar como forma de resistencia cultural y campo de experimentación a gran escala.

\section{BIBLIOGRAFÍA}

Auslander, P., «The performativity of performance documentation», en Perform, Repeat, Record: Live Art in History. (Bristol, Intellect, 2012)

BEDFORD, C., «The viral ontology of performance», en Perform, Repeat, Record: Live Art in History. (Bristol, Intellect, 2012)

Bench, H., «Screendance 2.o: Social Dance-Media». (Participations. Journal of Audience and Reception Studies, 7 [2], 2010)

Brannigan, E., DanceFilm. Choreography and the Moving Image (Nueva York, Oxford University Press, 2011).

Burt, R., Judson Dance Theater. Performative traces (Abingdon y Nueva York, Routledge, 2006).

De Keersmaeker, A. T., \& Cvejić, B., A Choreographer's Score: Fase, Rosas danst Rosas, Elena's Aria, Bartók (Gante, Mercatorfonds, 2012).

Franko, M., «Writing for the Body: Notation, Reconstruction, and Reinvention in Dance» (Common Knowledge, 17 [2], 2011), pp. 321-334.

Heathfield, A. y Jones, A. (eds.), Perform, Repeat, Record: Live Art in History (Bristol, Intellect Books Ltd. 2012)

HigGins, C. «Beyoncé pleasant but consumerist, says plagiarism row choreographer». (The Guardian, 11 de octubre de 2011). <https://www.theguardian.com/music/2011/oct/11/beyonce-pleasant-consumerist-plagiarism-row $>$ (06/06/2015) 
JENnings, L. «Beyonce v De Keersmaeker: can you copyright a dance move?». (The Guardian, 11 de octubre de 2011). <https://www.theguardian.com/stage/theatreblog/2011/oct/11/beyonce-de-keersmaeker-dance-move> (06/06/2015)

KAPPEnBerg, C., "The Logic of the Copy, from Appropriation to Choreography». (The International Journal of Screendance, 1, 2010)

KRAUT, Anthea, Choreographing Copyright: Race, Gender, and Intellectual Property Rights in American Dance. (Nueva York, Oxford University Press. 2016)

Kwastek, K., Aesthetics of Interaction in Digital Art (Cambridge, Massachusetts, The MIT Press, 2015)

LePecki, A., «Inscribing Dance», en A. Lepecki (Ed.), Of the Presence of the Body. Essays on Dance and Performance Theory (Middletowm, Wesleyan University Press, 2004), pp. 124-139.

-, «Choreography as apparatus of capture» (TDR: The Drama Review, Published by The MIT Press, 51[2], 2007), pp. 119-123.

LA Rocco, C. «Anne Teresa De Keersmaeker responds to Beyonce video». (The Performance Club, 2011). <http://theperformanceclub.org/2011/10/anne-teresa-dekeersmaeker-responds-to-beyonce-video/> (03/07/2015)

Mackrell, J. «Beyoncé, De Keersmaeker -and a dace reinvented by everyone». (The Guardian, (9 de octubre de 2013). <https://www.theguardian.com/stage/2013/ oct/o9/beyonce-de-keersmaeker-technology-dance> (07/06/2015)

McKinley, J. «Beyoncé accused of plagiarism over video». (The New York Times, 10 de octubre de 2011). <https://artsbeat.blogs.nytimes.com/2011/10/10/beyonce-accused-of-plagiarism-over-video/?_r=3> (06/o6/2015)

SchneIder, R., «Los restos de lo escénico (reelaboración)», en Isabel de Naverán (ed.), Hacer historia. Reflexiones desde la práctica de la danza. (Barcelona, Cuerpo de Letra Centro Coreográfico Galego, Mercat de les Flors, Institut del Teatre, 2010)

SteyerL, H. «In defense of the poor image» (e-flux Journal, 10, 2009): <http://www.eflux.com/journal/10/61362/in-defense-of-the-poor-image/> (10/03/2014)

Truemann, M. «Beyonce dance moves new video», (The Guardian, 10 de octubre de 2011). <https://www.theguardian.com/stage/2011/oct/10/beyonce-dance-movesnew-video $>$ (07/06/2015)

VenA, J. «Beyonce's ‘Countdown' Video Shoot Was 'Evolving, Spontaneous'». (MTV, 7 de octubre de 2011). <http://www.mtv.com/news/1672200/beyonce-countdownvideo-shoot/ > (09/09/2017).

\section{FUENTES ELECTRÓNICAS}

ABC News. «Beyonce Accused of Stealing Dance Moves; Superstar Responds, Saying She Was "Inspired" ». (2011). <https://www.youtube.com/watch?v=V1LCYoH3GwQ> (06/06/2015).

[BEYoncEVEVO]. «Beyoncé-Single Ladies (Put a Ring on it) (Video Version)». (2009). $<$ https://www.youtube.com/watch?v=4m1EFMoRFvY> (10/03/2018).

[BEYONCEVEVO]. «Beyoncé-Countdown». (2009). <https://www.youtube.com/ watch?v=2XY3AvVgDns $>(10 / 10 / 2015)$.

[FundifFERENT1]. «Split Screen: Beyonce "Countdown” vs Anne Teresa de Keersmaeker». <https://www.youtube.com/watch?v=PDTom514TMw> (04/07/2015). 
ROSAS/FABULEUS. RE:ROSAS. The fABULEUS Rosas Remix Project. (2013-2014) <http://www.rosasdanstrosas.be/en-home/> (05/07/2015).

[Rosas vZw]. «Rosas danst Rosas- The vocabulary in the second movement». (2013). https://www.youtube.com/watch?v=DVK_5IXOHBU (15/12/2016).

VV. AA., Anne Teresa de Keersmaeker Early Works [DVD] (Cineart, 2013).

Recibido: 15 de octubre de 2017

Aceptado para revisión: 21 de noviembre de 2017

Aceptado para publicación: 31 de mayo de 2018 